\title{
Comment on "A re-assessment of the safety of silver in household water treatment: rapid systematic review of mammalian in vivo genotoxicity studies"
}

Daniele Lantagne*, Justine Rayner, Anjuliee Mittelman and Kurt Pennell

\begin{abstract}
We wish to thank Fewtrell, Majuru, and Hunter for their article highlighting genotoxic risks associated with the use of particulate silver for primary drinking water treatment. The recent promotion of colloidal silver products for household water treatment in developing countries is problematic due to previously identified concerns regarding manufacturing quality and questionable advertising practices, as well as the low efficiency of silver nanoparticles to treat bacteria, viruses, and protozoa in source waters. However, in the conclusion statement of the manuscript, Fewtrell et al. state, "Before colloidal Ag or AgNP are used in filter matrices for drinking water treatment, consideration needs to be given to how much silver is likely to be released from the matrix during the life of the filter." Unfortunately, it appears Fewtrell et al. were unaware that studies of silver nanoparticle and silver ion elution from ceramic filters manufactured and used in developing countries have already been completed. These existing studies have found that: 1) silver ions, not silver nanoparticles, are eluted from ceramic filters treated with silver nanoparticles or silver nitrate; and, 2) silver ions have not been shown to be genotoxic. Thus, the existing recommendation of applying silver nanoparticles to ceramic filters to prevent biofilm formation within the filter and improve microbiological efficacy should still be adhered to, as there is no identified risk to people who drink water from ceramic filters treated with silver nanoparticles or silver nitrate. We note that efforts should continue to minimize exposure to silver nanoparticles (and silica) to employees in ceramic filter factories in collaboration with the organizations that provide technical assistance to ceramic filter factories.
\end{abstract}

Keywords: Ceramic filters, Elution, Genotoxicity, Silver ions, Silver nanoparticles, Water treatment

\section{Background}

We wish to thank Fewtrell, Majuru, and Hunter [1] for their article highlighting genotoxic risks associated with the use of particulate silver for primary drinking water treatment. The recent promotion of colloidal silver products for household water treatment in developing countries is problematic due to previously identified concerns regarding manufacturing quality and questionable advertising practices [2], as well as the low efficiency of silver nanoparticles to treat bacteria, viruses, and protozoa in source waters [3]. Potential genotoxic impacts of silver nanoparticles represent an additional concern, and highlights the need to carefully consider their use for household drinking water treatment in developing countries.

However, in the conclusion statement of the manuscript, Fewtrell et al. [1] state, "Before colloidal Ag or AgNP are used in filter matrices for drinking

* Correspondence: daniele.lantagne@tufts.edu;

Tufts University, Civil and Environmental Engineering, 200 College Avenue,

Medford, MA 02155, USA 
water treatment, consideration needs to be given to how much silver is likely to be released from the matrix during the life of the filter (e.g., work by Garboś and colleagues)." Unfortunately, the work completed by Garboś was not conducted in matrices similar to the ceramic filters manufactured in developing countries and the authors appear to be unaware that studies of silver nanoparticle and silver ion elution from ceramic filters manufactured and used in developing countries have already been completed [4].

\section{Main text}

Ceramic water filters are locally manufactured in more than 50 countries worldwide [5], are considered one of the most promising household water treatment methods [6], and application of silver nanoparticles ( $\mathrm{nAg}$ or AgNP) or silver nitrate $\left(\mathrm{AgNO}_{3}\right)$ has been shown to reduce biofilm formation within, and improve the microbiological efficacy of, ceramic water filters [7]. There are benefits and drawbacks to either form of silver applied to ceramic filters; silver nitrate can be purchase locally and is less expensive, while silver nanoparticles must be imported. However silver nitrate elutes more quickly, and silver concentrations in treated drinking water are more likely to exceed World Health Organization guidelines if applied at concentrations sufficient to improve disinfection performance $[4,7]$. Thus, silver nanoparticles are recommended for use in ceramic filter factories [5].

In the Mittelman et al. ${ }^{3}$ study, the impacts of nanoparticle detachment, dissolution, and cation exchange on silver elution was investigated as a function of influent water $\mathrm{pH}(5-9)$, ionic strength $(1-50 \mathrm{mM})$, and cation species $\left(\mathrm{Na}^{+}, \mathrm{Ca}^{2+}, \mathrm{Mg}^{2}\right)$ from filter disks painted with $0.03 \mathrm{mg} / \mathrm{g}$ casein-coated (nAg) or $\left(\mathrm{AgNO}_{3}\right)$. Under all conditions and regardless of the applied silver form, silver elution was controlled by the release of $\mathrm{Ag}^{+}$and subsequent cation exchange reactions within the ceramic filter. Overall, $>99 \%$ of silver was eluted as dissolved $\mathrm{Ag}^{+}$form rather than in the nanoparticle (nAg) form.

Thus, silver nanoparticles were not directly released into drinking water from ceramic filters impregnated with $\mathrm{nAg}$, rather $\mathrm{Ag}^{+}$eluted from ceramic filters (regardless of whether they were painted with silver nanoparticles or silver nitrate solution). Since all 16 studies identified in the Fewtrell et al. [1] review focused on the genotoxic risk of silver nanoparticles $(\mathrm{nAg})$, rather than the risk from silver ions, the conclusions of the Fewtrell et al. [1] are not applicable to exposure from drinking water treated with locallymanufactured ceramic filters impregnated with silver nanoparticles or silver nitrate.
Additionally, a recent study by Li et al. [8] examined the mechanisms of genotoxicity of $\mathrm{nAg}$ and $\mathrm{Ag}^{+}$, using a mammalian cell micronucleus assay. Their work incorporated gene expression analysis, measurements of oxidative stress, and the use of a reactive oxygen species scavenger and a chelator to evaluate the role of $\mathrm{Ag}^{+}$in the genotoxicity of $\mathrm{nAg}$. The authors found that silver ions $(\mathrm{Ag}+)$ did not release hydroxyl radicals and concluded: "These results suggest that, although both AgNPs and $\mathrm{Ag}^{+}$can cause genotoxicity via producing oxidative stress, the mechanisms are different and the nanoparticles, but not the released ions, are mainly responsible for the genotoxicity of AgNPs."

Thus, the primary exposure to silver nanoparticles with regards to ceramic filters is to employees during production, not users drinking the water. In ceramic filter factories, silver is imported in either a powder or concentrated liquid form [5]. Employees typically prepare a concentrated silver solution once per week or month, depending on production, and dilute the solution as needed for application to ceramic filters. It is currently recommended that employees wear N95 masks to reduce exposure when preparing powdered or liquid silver nanoparticles, and wear gloves when applying dilute solution onto filters [5]. Fewtrell et al. [1] are correct in stating that "health and safety precautions are not strictly adhered to in the production of ceramic filters in low income countries" [9] and while the only study included in the Fewtrell et al. [1] paper that evaluated exposure via inhalation found no difference, maintaining precautionary administrative controls and personal protection equipment use to minimize exposure when handling silver is still advised. Additionally, the key health risk of silica exposure during clay processing for employees in ceramic filter factories should also be ameliorated with personal protective equipment [10].

\section{Conclusions}

In summary, based on existing data that Fewtrell et al. [1] did not reference: 1) silver ions, not silver nanoparticles, are eluted from ceramic filters treated with silver nanoparticles or silver nitrate; 2) silver ions have not been shown to be genotoxic; 3) the existing recommendation of applying silver nanoparticles to ceramic filters to prevent biofilm formation within the filter and improve microbiological efficacy should still be adhered to; and, 4) efforts should continue to minimize exposure to silver nanoparticles (and silica) to employees in ceramic filter factories in collaboration with the organizations that provide technical assistance to ceramic filter factories. 


\section{Author's response to: Comment on "A re-assessment of the safety of silver in household water treatment: rapid systematic review of mammalian in vivo genotoxicity studies"}

Paul R. Hunter ${ }^{1 *}$, Batsirai Majuru ${ }^{1}$ and Lorna Fewtrell ${ }^{2}$

${ }^{1}$ Norwich Medical School, University of East Anglia, Norwich NR4 7TJ, UK

${ }^{2}$ Centre for Research into Environment and Health, University of Aberystwyth, Aberystwyth, UK

\begin{abstract}
We thank Lantagne and colleagues for their comments on our recent paper. As we stated in our original paper we could find no evidence that ionic silver was associated with genotoxicity and the balance of evidence indicates that it is not. About whether ceramic filters release nanoparticles in routine use, we do not consider that the single laboratory study is necessarily sufficient to assess the risk over the lifetime of a single ceramic filter during routine use in the field. We do agree with Lantagne and colleagues that risk from occupational exposure to silver nanoparticles during production of filters in low income countries with inadequate personal protection is a significant concern.
\end{abstract}

\section{Keywords}

SilverNanoparticlesGenotoxicityDNA

damageNanocomposites

\section{Main text}

We thank Lantagne and colleagues for their comments on our recent paper [1]. We would like to respond to two points. Firstly about the potential genotoxicity of ionic silver. We agree that ionic silver does not appear to be genotoxic and we stated this very clearly in our paper: "We did not find any papers which suggested that in vivo exposure to ionic silver posed a threat of genotoxicity, but those few studies that reported on ionic silver found no effect even from in vitro studies". Given that the recent paper that Lantagne cites [8] was not an in vivo study either but an in vitro study, it would have not been included in our review and does not alter our conclusion in this regard.

On the issue of release of nanoparticles from silver nanocomposites. We did state that "Before colloidal Silver or Silver Nanoparticles are used in filter matrices for drinking water treatment, consideration needs to be given to how much silver is likely to be released from the matrix during the life of the filter". Release of nanoparticles from nanocomposites is certainly a cause for concern $[11,12]$. However, there are many different types of filter and we did not feel there was sufficient evidence to debate whether certain filters were more or less likely to release nanoparticles over their lifetime than others. Lantagne et al. cite their paper to show that in the laboratory at least it is ionic silver and not nanoparticles that is released [4]. We would, however, question whether the results of this carefully controlled laboratory based study can be extrapolated to the lifetime of a ceramic filter's use when such filters may be subject to a range of abuse not modelled in these laboratory experiments.

Finally, we would join with Lantagne and colleagues in stressing the potential occupational risks associated with the use of silver nanoparticles in manufacturing in low income countries. The use of appropriate personal protective equipment is essential and consideration should probably also be given to the need for health screening of workers.

Abbreviations

$\mathrm{Ag}+$ : Silver ions; $\mathrm{AgNO}_{3}$ : Silver nitrate; AgNPor nAg: Silver nanoparticles

\author{
Acknowledgments \\ Not applicable \\ Funding \\ Not applicable \\ Availability of data and materials \\ Not applicable \\ Authors' contributions \\ DL wrote the draft comment, revised based on co-author input, and \\ submitted comment. JR, AM, and KP reviewed the comment. All authors \\ read and approved the final manuscript.
}

Ethics approval and consent to participate

Not applicable

Consent for publication

Not applicable

Competing interests

The authors declare no competing interests.

\section{Publisher's Note}

Springer Nature remains neutral with regard to jurisdictional claims in published maps and institutional affiliations.

Received: 13 July 2017 Accepted: 1 November 2017 Published online: 13 November 2017

\section{References}

1. Fewtrell L, Majuru B, Hunter PR. A re-assessment of the safety of silver in household water treatment: rapid systematic review of mammalian in vivo genotoxicity studies. Environ Health. 2017;16:1.

2. Murray A, Pierre-Louis J, Joseph F, Sylvain G, Patrick M, Lantagne D. Need for certification of household water treatment products: examples from Haiti. Tropical Med Int Health. 2015;20(4):462-70. 
3. Fewtrell L. Silver: water disinfection and toxicity. Geneva: Centre for Research into Environment and Health, World Health Organization; 2014. http://www.who.int/water_sanitation_health/dwq/chemicals/Silver_water_ disinfection toxicity_2014V2.pdf. Accessed 11 July 2017.

4. Mittelman AM, Rayner J, Lantagne D, Pennell K. Silver dissolution and release from ceramic water filters. Environ Sci Technol. 2015;49(14):8515-22.

5. CMWG. Best practice recommendations for local manufacturing of ceramic pot filters for household water treatment. Ed. 1 ed. Atlanta: Ceramic Manufacturing Working Group, Centers for Disease Control and Prevention; 2011. https://s3.amazonaws.com/PfP/Best+Practice+Recommendations+for +Manufacturing+Ceramic+Pot+Filters+June2011.pdf. Accessed 11 July 2017.

6. Hunter PR. Household water treatment in developing countries: comparing different intervention types using meta-regression. Environ Sci Technol. 2009;43(23):8991-7.

7. Rayner J, Zhang H, Schubert J, Lennon P, Lantagne D, Oyanedel-Craver V. Laboratory investigation into the effect of silver applied on the bacteriological removal efficacy of filter material for use on locally-produced ceramic water filters for household drinking water treatment. ACS Sustain Chem Eng. 2013;1(7):737-45.

8. Li Y, Qin T, Ingle T, Yan J, He W, Yin JJ, Chen T. Differential genotoxicity mechanisms of silver nanoparticles and silver ions. Arch Toxicol. 2017;91(1):509-19.

9. Rayner J, Skinner B, Lantagne D. Current practices in manufacturing locally-made ceramic pot filters for water treatment in ceveloping countries. Journal of Water, Sanitation, and Hygiene for Development. 2013;3(2):252-61.

10. Leung CC, Yu ITS, Chen W. Silicosis. Lancet. 2012;379(9830):2008-18.

11. Froggett SJ, Clancy SF, Boverhof DR, Canady RA. A review and perspective of existing research on the release of nanomaterials from solid nanocomposites. Particle and fibre toxicology. 2014;11(1):17.

12. Mackevica A, Foss HS. Release of nanomaterials from solid nanocomposites and consumer exposure assessment-a forward-looking review. Nanotoxicology. 2016;10(6):641-53

\section{Submit your next manuscript to BioMed Central and we will help you at every step:}

- We accept pre-submission inquiries

- Our selector tool helps you to find the most relevant journal

- We provide round the clock customer support

- Convenient online submission

- Thorough peer review

- Inclusion in PubMed and all major indexing services

- Maximum visibility for your research

Submit your manuscript at www.biomedcentral.com/submit 